\title{
Energy metabolism of young rats after early postnatal overnutrition
}

\author{
Petra Wiedmer, Sylvia Ortmann and Susanne Klaus* \\ Department of Biochemistry and Physiology of Nutrition, German Institute of Human Nutrition (DlfE) \\ 14558 Potsdam-Rehbrücke, Germany
}

(Received 12 October 2001 - Revised 2 April 2002 - Accepted 9 May 2002)

\begin{abstract}
Early postnatal overnutrition (PNO) induced by restricting litter size in rats leads to increased body-weight (BW) and body-fat gain in later life. PNO rats are used as an animal model of moderate obesity and early hyperinsulinism. We investigated whether the increased adiposity could be due to a decreased energy expenditure. Male newborn Wistar rats were raised in litters of either two (SL) or twelve pups (NL), weaned at 4 weeks of age and subsequently fed ad libitum. BW was recorded continuously until 12 weeks of age. Daily energy intake, total daily energy expenditure (EE, measured by indirect calorimetry) and body composition were measured in weaned pups at 5, 8 and 12 weeks of age. SL rats displayed increased BW compared with NL rats from week 2 to 5 and again from week 10 to 12 . Lean body mass, body fat and protein content and total EE were increased in SL rats at week 5. The same linear correlation described the relationship between BW and total EE in NL and SL rats. At week 8 to 12 no differences in energy metabolism could be found, but the total fat content was increased in SL rats at week 12. Energy balance, i.e. assimilated energy minus EE, was no different between SL and NL at any time that it was measured. We conclude that although PNO rats display increased adiposity in early life, there seem to be no long-lasting effects on energy metabolism in later life, even if a tendency to increased adiposity can still be detected.
\end{abstract}

Obesity: Energy expenditure: Small litters: Body composition

Overweight in early life induced by early postnatal overnutrition (PNO) is a risk factor for development of obesity and associated cardiovascular diseases in later life (Martorell et al. 2001). Reduction of pre-weaning litter size in rats and mice leads to increased fat deposition of pups during the sucking period and can also result in increased adult body mass and fat content (Knittle \& Hirsch, 1968; Faust et al. 1980). It has also been shown that rats from small litters (SL) can develop persistent hyperinsulinaemia, increased systolic blood pressure, and hyperleptinaemia (Cryer \& Jones, 1980; You et al. 1990; Plagemann et al. 1992, 1999). Although it is quite clear that rats reared in SL show increased fat deposition at the end of the sucking period, there are controversial reports in the literature as to whether this has a longlasting effect, and whether SL rats display hyper-, normo- or even hypophagia after weaning (Miller \& Personage, 1972; Wurtman \& Miller, 1976; Faust et al. 1980; Hausberger \& Volz, 1984; Aust et al. 1985; Lambert \& Koeslag, 1992; Plagemann et al. 1992). One reason for this could be that the number of pups considered as 'SL' differed from two to six. On the other hand, many studies compared SL with large litters (sixteen to twenty-four pups) in which pups were undernourished (Knittle \& Hirsch, 1968; Oscai \& McGarr, 1978; Faust et al. 1980). Furthermore, there seems to be a sex effect, with males being more responsive to early PNO than females (Cryer \& Jones, 1980; Bassett \& Craig, 1988; Lambert \& Koeslag, 1992) and strain differences (Hausberger \& Volz, 1984). The importance of the genetic background has been emphasised by a recent study, which demonstrated that heterozygous $+/ f a$ pups raised in small litters showed a greater increase in body fat than wildtype $+/+$ pups, although they do not show an overt phenotype under normal feeding conditions (Schmidt et al. 2000). Moreover, detailed studies examining the energy metabolism of PNO rats after weaning and in later life are still lacking. It is not known whether permanent changes in energy expenditure (EE) could contribute to development and persistence of obesity in this model. Our objective was therefore to re-evaluate the model of early PNO, especially with regard to energy metabolism.

\footnotetext{
Abbreviations: BW, body weight; EE, energy expenditure; LBM, lean body mass; NL, normal litter; PNO, postnatal overnutrition; SL, small litter.

* Corresponding author: Dr Susanne Klaus, fax +49 33 200/88 500, email Klaus@www.dife.de
} 


\section{Material and methods}

\section{Experimental design}

All animal experiments were performed in accordance with the guidelines of the ethics committee of the Ministry of Agriculture, Nutrition and Forestry (State Brandenburg, Germany). Shoe-Wistar rats (12-week-old, Tierzucht Schoenwalde, Schoenwalde, Germany) were housed in a temperature-controlled room $\left(22^{\circ} \mathrm{C}\right)$ with a $12 \mathrm{~h}$ lightdark cycle and with food and water ad libitum. Throughout the experiment, all animals received commercial rat chow (maintenance diet no 1326; Altromin GmbH, Lage, Germany). Male and female rats were housed together for $5 \mathrm{~d}$ to mate. During the gestation and lactation periods dams were housed individually. One day after birth, male pups were distributed randomly and assigned to either SL (two pups per litter) or normal litters (NL twelve pups per litter). Pups were weaned at 4 weeks of age and subsequently housed with two (SL) or three (NL) pups per cage. At 5 weeks of age six animals from SL and NL each were placed in metabolism cages and subjected to measurement of energy assimilation ( $48 \mathrm{~h}$ ) followed by measurement of EE using indirect calorimetry $(48 \mathrm{~h})$ after which animals were killed for carcass analysis. The same was performed with rats at 8 and 12 weeks of age with the exception that energy assimilation was measured over a $3 \mathrm{~d}$ period and that different animals were used for measurement of EE. In week 8 and 12, animals used for measurement of EE were weight matched.

\section{Body composition}

After the indirect calorimetry, animals were killed and stored frozen $\left(-20^{\circ} \mathrm{C}\right)$ until chemical analysis of body composition as described elsewhere (Association of Official Analytical Chemists, 1990; Proll et al. 1998). For this, complete carcasses were autoclaved in $30 \mathrm{ml} \mathrm{HCl}$ $(50 \mathrm{ml} / \mathrm{l})$ at $121^{\circ} \mathrm{C}$ for $3 \mathrm{~h}$, homogenised and lyophilised. The total energy content of each carcass was measured by analysis of a subsample using a bomb calorimeter (IKA, Werke GbmH \& Co. KG, Staufen, Germany; C400). The lipid content was assayed by extraction with light petroleum $\left(40-60^{\circ} \mathrm{C}\right)$ in a Soxhlet extractor and calculated as the difference between dry carcass weight before and after lipid extraction. Lean body mass was calculated as carcass mass minus lipid mass. Protein content was determined by Kjehldahl quantification of $\mathrm{N}$ content.

\section{Energy metabolism}

For measurement of energy assimilation (at 5, 8 and 12 weeks of age) individual animals were placed for 2 or $3 \mathrm{~d}$ in metabolism cages allowing collection of faeces and urine separately. The energy contents of rat chow and faeces were determined using bomb calorimetry. The energy content of urine was calculated by measurement of $\mathrm{N}$ content: $1 \mathrm{~g} \mathrm{~N}$ was considered to correspond to $22.7 \mathrm{~kJ}$ (Hoffmann \& Klein, 1980). Assimilated energy was calculated by subtracting the energy content of urine and faeces from the energy content of consumed food.
The mean energy assimilation was $73.6 \%$ energy intake and was not influenced by age or treatment.

$\mathrm{EE}$ of individual rats (at 5, 8 and 12 weeks of age) was measured over $2 \mathrm{~d}$ using indirect calorimetry as described by Klaus et al. (1998). Briefly, $\mathrm{O}_{2}$ consumption and $\mathrm{CO}_{2}$ production were determined every $6 \mathrm{~min}$ in an open-circuit respirometric system and $\mathrm{EE}$ was calculated according to Weir (1949). Total EE was calculated as a mean value for $24 \mathrm{~h}$. Energy balance was calculated by subtracting total EE from assimilated energy, assuming a mean energy assimilation of $73.6 \%$.

\section{Statistics}

Results are presented as mean values with their standard errors. Differences between SL and NL groups were assessed using unpaired Student's $t$ test (SPSS for Windows 8.0, 1998; SPSS Inc., Chicago, IL, USA). Differences were regarded as significant at $P<0.05$. Linear correlations were calculated using least-square regressions.

\section{Results}

In comparison with NL, male rat pups reared in SL had a significantly $(P<0 \cdot 05)$ increased body weight $(\mathrm{BW})$ from the second week of the sucking period up to 5 weeks, i.e. at about puberty (Fig. 1). At weaning, the body mass of SL rats was $35 \%$ greater than that of NL rats and at 5 weeks it was still greater by $25 \%$. From 6 to 9 weeks (corresponding to late puberty) $\mathrm{BW}$ differences were no longer significant, but from postpuberty to early adulthood (week 10 to 12$)$ SL rats again displayed a significantly $(P<0.05)$ higher mean BW than NL rats (Fig. 1(B)). The mean energy assimilation was $73.6 \%$ energy intake and was not influenced by age or treatment.

In accordance with the increased BW of SL rats at week 5 , they also showed an increased lean body mass (LBM), absolute body fat and body protein content and increased total EE. Only total energy intake, although increased, did not reach statistical significance due to large inter-individual variations (Table 1). Relative body fat, but not relative body protein, was also increased in SL rats at week 5, indicating an increased adiposity (Fig. 2). Using the data on energy intake and EE (which were measured simultaneously), we could also estimate the energy balance or energy retention, i.e. the difference between intake and expenditure. Energy intake in this respect refers to assimilated energy, which was $73.6 \%$ total intake as described earlier. As can be seen in Table 1, both groups SL and NL had the same energy retention of about $56 \mathrm{~kJ} / \mathrm{d}$, indicating that energy balance was not different between NL and SL at 5 weeks of age.

Fig. 3 shows the relationship between total EE and BW or LBM respectively in 5-week-old rats. Results for both SL and NL groups fall on the same regression line, with BW explaining $78.2 \%$ and LBM $73.5 \%$ of the variation in total $\mathrm{EE}(P<0.001$ in both cases).

In order to investigate a possible reprogramming of energy metabolism by early PNO independent of BW, we used weight-matched animals from SL and NL for further analysis of energy metabolism in later life (week 

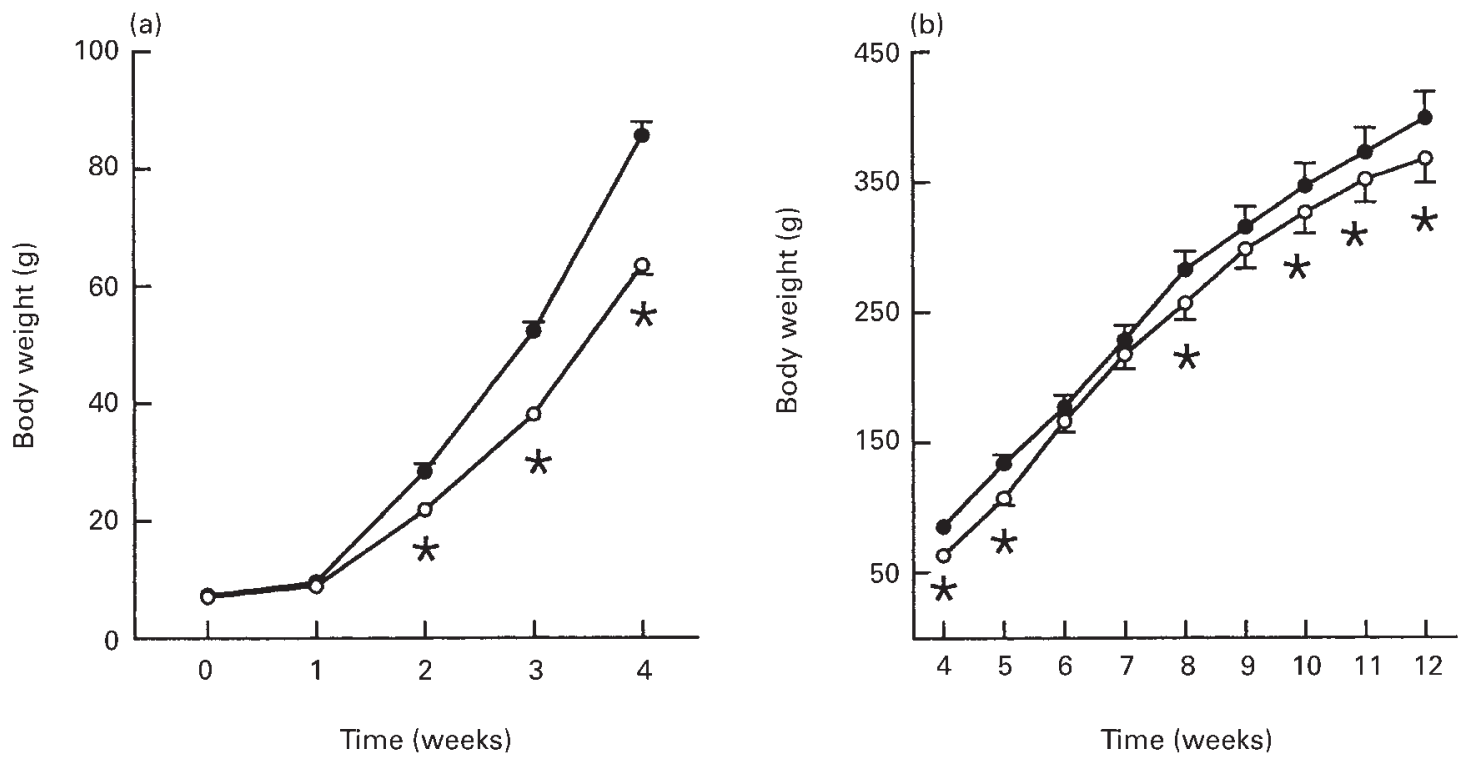

Fig. 1. Body-weight gain of rats from small litters (SL, two pups per litter; $(\bullet)$ compared with rats from normal litters (NL, twelve pups per litter; (O). (a), body-weight gain from birth until weaning; (b), body-weight gain after weaning. For details of diets and procedures, see p. 302. Values are means for six litters per group with standard errors shown by vertical bars (where bar is not visible, it is within the symbol size). Mean values were significantly different from those of SL group. ${ }^{*} P<0.05$.

8 and 12). As can be seen in Table 2, no differences between SL and NL rats could be detected in LBM, body protein, as well as energy intake, EE and energy balance. However, body fat was increased by about $8 \mathrm{~g}(17 \%)$ in 12-week-old SL rats compared with NL rats.

Fig. 4 shows the relationship between $\mathrm{BW}$ and total EE for all three age groups. As in week 5, total EE also showed a strong correlation $(P<0 \cdot 001)$ with $\mathrm{BW}$ in week 8 and 12. Regression equations are as follows: $y=$ $0.529 x+58.8, r 0.82$ (week 8) and $y=0.747 x-72 \cdot 6$, $r 0.89$ (week 12).

\section{Discussion}

The present study confirms that early PNO induced by reduction of litter size results in an increased BW shortly after weaning. During adolescence a 'catch up' growth in NL rats seemed to occur, resulting in similar BW in both groups from week 6 to about week 9 (Fig. 1). This phenomenon was also evident in other studies (Bassett \& Craig, 1988; Voits et al. 1996). However, from week 10 onwards, a slightly, but significantly $(P<0.05)$ elevated BW was apparent in SL rats, indicating a long-lasting influence of PNO on BW gain. However, in week 5, BW differences between NL and SL rats were most pronounced. This was due to an absolute gain of all body compartments, i.e. lean body mass, body protein and body fat (Table 1). In relative terms, body fat mass but not body protein was increased, indicating a preferential gain in fat mass and not muscle mass in the SL rats (Fig. 2).

Total energy intake at week 5 was slightly but not significantly higher in the SL group (Table 1), not supporting hyperphagia in SL rats, especially when considering that SL animals were about $25 \%$ heavier than NL rats. Previous studies report either hyperphagia when comparing total food intake (Oscai \& McGarr, 1978; Bassett \& Craig, 1988; Plagemann et al. 1992; Voits et al. 1996) or hypophagia when related to body mass (Miller \& Personage,

Table 1. Body composition and energy metabolism of rats in small or normal litters at 5 weeks of age* (Mean values with their standard errors for six animals per group)

\begin{tabular}{|c|c|c|c|c|c|}
\hline & \multicolumn{2}{|c|}{$\mathrm{NL} \dagger$} & \multicolumn{2}{|c|}{ SL† } & \multirow{2}{*}{$\begin{array}{c}\text { Statistical significance } \\
\text { of difference between } \\
\text { groups: } P\end{array}$} \\
\hline & Mean & SEM & Mean & SEM & \\
\hline Body weight (g) & $106 \cdot 1$ & $2 \cdot 7$ & $135 \cdot 3$ & 4.2 & $<0.001$ \\
\hline Lean body mass (g) & 99.8 & $2 \cdot 6$ & $123 \cdot 4$ & 4.0 & 0.001 \\
\hline Body fat content (g) & $7 \cdot 1$ & 0.4 & 11.9 & 0.4 & $<0.001$ \\
\hline Body protein content $(\mathrm{g})$ & $20 \cdot 4$ & 0.6 & $24 \cdot 6$ & $1 \cdot 1$ & 0.007 \\
\hline Energy intake $(\mathrm{kJ} / \mathrm{d})$ & $290 \cdot 7$ & $4 \cdot 1$ & 324.6 & $15 \cdot 4$ & $0.080 \ddagger$ \\
\hline Total EE $(\mathrm{kJ} / \mathrm{d})$ & $157 \cdot 8$ & $4 \cdot 3$ & $182 \cdot 2$ & $5 \cdot 0$ & $0.004^{\top}$ \\
\hline Energy balance $(\mathrm{kJ} / \mathrm{d})$ & $56 \cdot 2$ & 4.4 & $56 \cdot 7$ & 8.5 & NS \\
\hline
\end{tabular}

NL, normal litter; SL, small litter; EE, energy expenditure.

${ }^{*}$ For details of diets and procedures, see p. 302.

$† \mathrm{NL}$, twelve pups per litter; SL, two pups per litter.

$\ddagger N S$. 


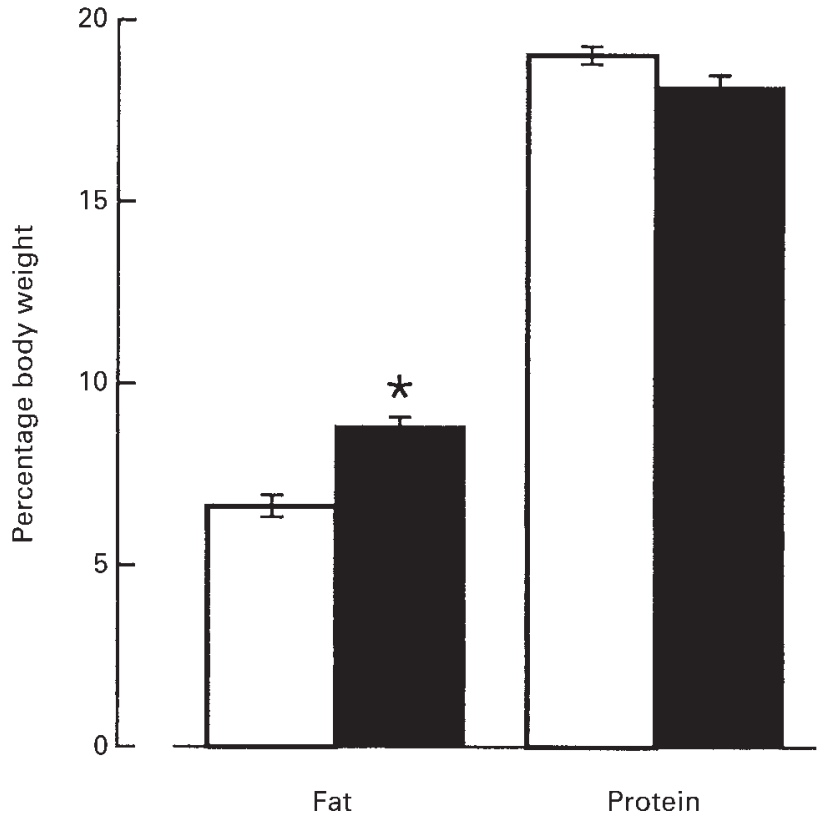

Fig. 2. Body fat and body protein content of rats from small litters (SL, two pups per litter; $\mathbf{\square}$ ) and normal litters (NL, twelve pups per litter; $\square$ ) at 5 weeks of age. For details of diets and procedures, see p. 302. Values are means for six litters per group with standard errors shown by vertical bars. Mean value was significantly different from the NL group. ${ }^{*} P<0.05$.

1972; Parizková \& Petrásek, 1979; Aust et al. 1985). However, energy balance was not determined in these studies and our present results show that even by 5 weeks of age there was no difference in energy retention between the groups. This indicates that the greater BW and adiposity in SL rats is a result of different energy budgets during the pre-weaning period only.

Total daily EE was increased in SL rats at week 5 despite increased adiposity, a phenomenon also observed in obese human subjects (Ravussin et al. 1982; Prentice et al. 1986). As in human subjects, this is due to the fact that not only body fat was increased in SL rats, but also LBM, which is the main determinant of resting EE (Ravussin et al. 1982; DeLany \& Lovejoy, 1996). It is generally agreed that if available, LBM or fat-free mass is a better variable for normalisátion than total body mass because of the low metabolic activity of adipose tissue. However, the contribution of fat mass to total EE increases with increasing fat mass (Garby et al. 1988). A common problem in the investigation of energy metabolism is the normalisation for differences in BW or size (Himms-Hagen, 1997). Correlation of total EE with BW or LBM (Fig. 3) showed that in the present study, BW was a better predictor of EE than LBM. Still, there was a strong linear correlation of EE with both BW and LBM. It should be noted that both regression equations have a non-zero intercept; this was also reported in studies on human subjects (Ravussin \& Bogardus, 1989; DeLany \& Lovejoy, 1996). This shows clearly that simply dividing total EE by BW can lead to erroneous results, i.e. an underestimation of total $\mathrm{EE}$ at higher BW. As is evident from Fig. 3, EE of individual SL and NL rats at week 5 fall on the same regression line when correlated with BW or LBM, indicating that (a)

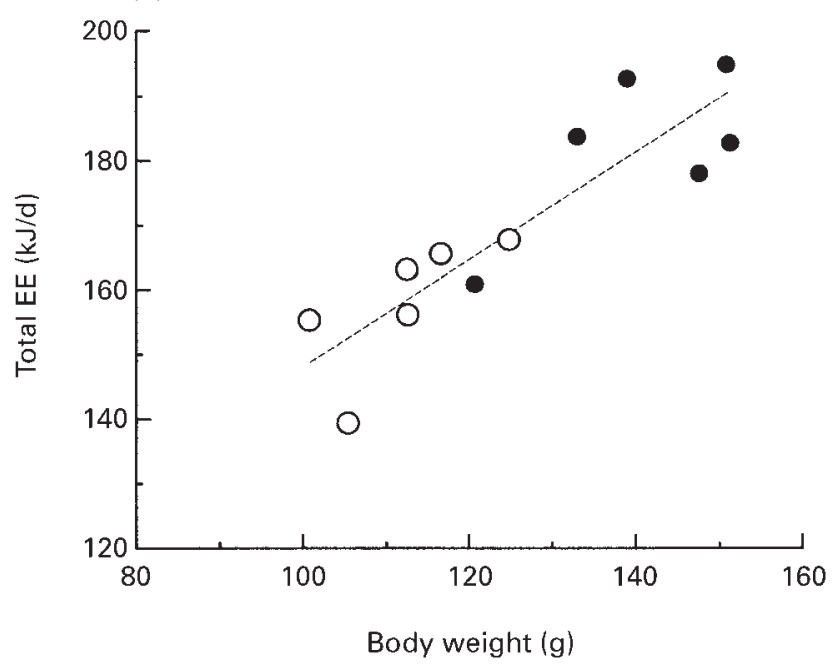

(b)

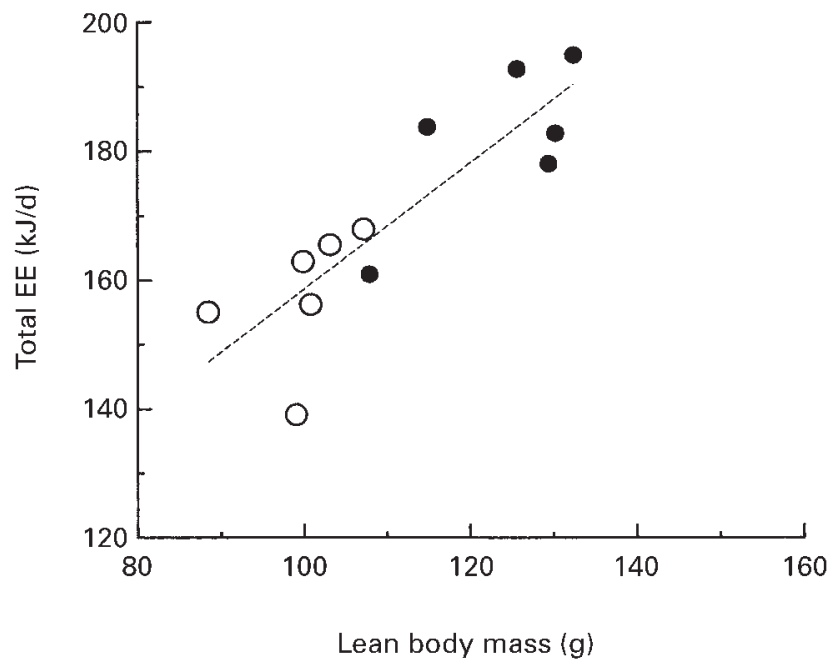

Fig. 3. Relationship between body weight (a) and lean body mass (b) and total energy expenditure (EE) in small litters (SL, two pups per litter; $\bullet$ ) and normal litters (NL, twelve pups per litter; $\bigcirc)$. For details of diets and procedures, see p. 302. ----, Least-square regressions described by: (a) $y=0.833 x+64.8$ (r 0.782, $P<0.001)$, (b) $y=0.979 x+60.7(r 0.735, P<0.001)$.

there were no systematic differences in EE between SL and NL rats. This is also evident in the other age groups: both at 8 and 12 weeks, BW explained 68 and $75 \%$ respectively, of individual EE (Fig. 4). It is also apparent from Fig. 4 that within each age group, the relationship between $\mathrm{BW}$ and total $\mathrm{EE}$ is different from the overall correlation.

A further complication in the comparison of SL and NL rats during adolescence and early adulthood arises from the fact that in rats between approximately 25 and $90 \mathrm{~d}$ of age, relative body fat content increases and energy intake and $\mathrm{EE}$ decrease, even if corrected for BW or body protein (Iossa et al. 1999). Thus, it can not be excluded that the increased adiposity observed at week 5 was merely a consequence of advanced growth and maturation induced by PNO. In order to avoid both this problem and the difficulties of data normalisation discussed earlier, we investigated 
Table 2. Body composition, energy intake and total daily energy expenditure of weight-matched rats in small or normal litters at 8 and 12 weeks*

(Mean values with their standard errors for six litters per group)

\begin{tabular}{|c|c|c|c|c|c|c|c|c|c|c|}
\hline & \multicolumn{5}{|c|}{ Week 8} & \multicolumn{5}{|c|}{ Week 12} \\
\hline & \multicolumn{2}{|c|}{$\mathrm{NL} \dagger$} & \multicolumn{2}{|c|}{ SL† } & \multirow{2}{*}{$\begin{array}{c}\text { Statistical significance } \\
\text { of difference between } \\
\text { groups: } P\end{array}$} & \multicolumn{2}{|c|}{ NL† } & \multicolumn{2}{|l|}{ SL† } & \multirow{2}{*}{$\begin{array}{c}\text { Statistical significance } \\
\text { of difference between } \\
\text { groups: } P\end{array}$} \\
\hline & Mean & SEM & Mean & SEM & & Mean & SEM & Mean & SEM & \\
\hline Body weight (g) & $290 \cdot 5$ & 7.4 & $290 \cdot 4$ & 11.5 & NS & 398.6 & 9.4 & $395 \cdot 7$ & 8.6 & NS \\
\hline Lean body mass (g) & 240.9 & 14.5 & $242 \cdot 8$ & $20 \cdot 8$ & NS & $322 \cdot 0$ & $26 \cdot 1$ & $312 \cdot 4$ & $20 \cdot 3$ & NS \\
\hline Body fat content $(\mathrm{g})$ & 23.1 & $5 \cdot 2$ & 23.9 & $5 \cdot 3$ & NS & 45.6 & 4.9 & 53.5 & 6.4 & 0.04 \\
\hline Body protein content (q) & $54 \cdot 1$ & 4.0 & 54.2 & 4.7 & NS & $75 \cdot 0$ & $6 \cdot 8$ & $72 \cdot 3$ & $4 \cdot 1$ & NS \\
\hline Energy intake $(\mathrm{kJ} / \mathrm{d})$ & 418.3 & $13 \cdot 7$ & $426 \cdot 0$ & $19 \cdot 7$ & NS & $407 \cdot 2$ & $14 \cdot 8$ & 418.7 & $35 \cdot 7$ & NS \\
\hline Total EE $(\mathrm{kJ} / \mathrm{d})$ & $213 \cdot 3$ & $3 \cdot 3$ & 211.3 & 8.1 & NS & 224.3 & $7 \cdot 4$ & 224.0 & $8 \cdot 2$ & NS \\
\hline Energy balance $(\mathrm{kJ} / \mathrm{d})$ & 94.6 & $8 \cdot 6$ & $102 \cdot 2$ & 11.2 & NS & 75.4 & $7 \cdot 8$ & 84.2 & 20.5 & NS \\
\hline
\end{tabular}

NL, normal litter; SL, small litter; EE, energy expenditure.

${ }^{*}$ For details of diets and procedures, see p 302.

$\dagger \mathrm{NL}$, twelve pups per litter; SL, two pups per litter.

weight-matched SL and NL rats in order to detect possible intrinsic changes induced by PNO. However, as is evident from Table 2 and Fig. 4, there were no indications for any changes in total EE or energy balance, even at week 12 when body fat was increased in SL rats.

There are only very scarce results in the literature about $\mathrm{EE}$ in SL animals in comparison with NL animals. It has been reported that SL rats show a reduced postprandial EE at 7-9 weeks of life (Aust et al. 1986). In the present study, we found that total daily EE was virtually the same for SL and NL rats at week 8 and 12. As postprandial thermogenesis accounts for only about $10-15 \%$ total daily EE, it is evident that even if postprandial EE was reduced in our present study, it could not lead to significant changes in total EE given the relatively large inter-individual variations in EE.

In studies of human subjects, both perinatal undernutrition and overnutrition have been implicated as risk factors

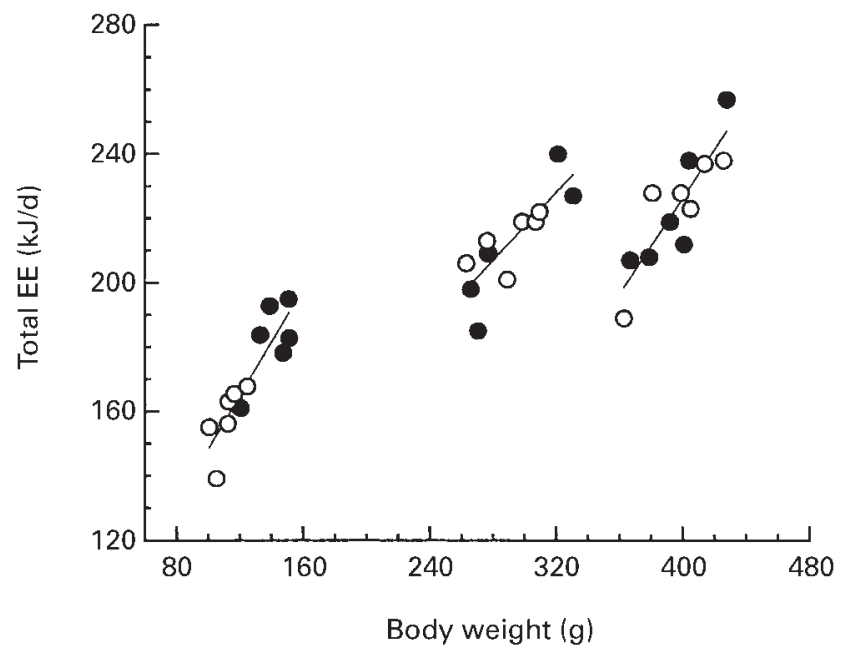

Fig. 4. Relationship between body weight and total daily energy expenditure (EE) for all age groups of rats in small litters (SL, two pups per litter; $\bullet$ ) and normal litters (NL, twelve pups per litter; O). For details of diets and procedures, see p. 302. ---, Least-square regressions $(P<0.001)$ calculated separately for the three age groups. for developing obesity in later life. Breast-feeding was found to have a protective effect of childhood obesity, although breast-fed infants are fatter than formula-fed babies in the first months of life (Martorell et al. 2001). Our present findings, together with the great inconsistency of results from previous animal studies, support the view that early postnatal nutrition per se might not have a very large influence on energy metabolism and obesity in later life. Rather, an interaction with other factors such as sex or genetic background seems to be necessary. It has been shown recently that nutritional influences during pregnancy, i.e. during fetal growth, can reprogramme variables of energy metabolism and are further amplified by postnatal hyperenergetic nutrition (Vickers et al. 2000). Using the same rat strain as in the present study, we found that prenatal exposure to a maternal high-protein diet resulted in an increased fat mass and decreased total EE in adolescent rats, whereas a postnatal high-protein diet had only minor effects on BW (Daenzer et al. 2002). Together, this indicates that prenatal nutritional influences might be more important than postnatal exposure in programming of energy metabolism in later life. Nevertheless, it would be interesting to investigate the effect of PNO on energy metabolism in an animal model like the heterozygous $+/ f a$ rat, which apparently is more susceptible to this kind of nutritional manipulation (Schmidt et al. 2000).

In conclusion, the present study shows that early PNO leads to increased BW and adiposity in prepubertal male Shoe-Wistar rats, which could be due to advanced growth, but not to changes in overall energy budget. Furthermore, there is no evidence for persistent changes in overall energy metabolism in later life even if PNO can result in a slightly increased adiposity in adulthood.

\section{Acknowledgements}

We are grateful to Dr L. Aust for valuable discussion on methods and data. Thanks are due to Carola Plaue for excellent technical assistance. 


\section{References}

Association of Official Analytical Chemists (1990) Official Methods of Analysis, 15th ed., Arlington, VA: AOAC.

Aust L, Noack R, Eschrich H, Proll J \& Zahn L (1985) Influence of early postnatal overnutrition on growth, body composition and energy utilization rats. Nahrung 29, 617.

Aust L, Noack R \& Proll J (1986) The influence of early postnatal overnutrition on postprandial energy expenditure in rats. Nahrung 30, 451-452.

Bassett DR \& Craig BW (1988) Influence of early nutrition on growth and adipose tissue characteristics in male and female rats. Journal of Applied Physiology 64, 1249-1256.

Cryer A \& Jones HM (1980) The development of white adipose tissue. Effect of litter size on the lipoprotein lipase activity of four adipose-tissue depots, serum immunoreactive insulin and tissue cellularity during the first year of life in male and female rats. Biochemical Journal 186, 805-815.

Daenzer M, Ortmann S, Klaus S \& Metges CC (2002) Prenatal high protein exposure decreases energy expenditure and increases adiposity in young rats. Journal of Nutrition 132, $142-144$.

DeLany JP \& Lovejoy JC (1996) Energy expenditure. Endocrinology and Metabolism Clinics of North America 25, 831846.

Faust IM, Johnson PR \& Hirsch J (1980) Long-term effects of early nutritional experience on the development of obesity in the rat. Journal of Nutrition 110, 2027-2034.

Garby L, Garrow JS, Jorgensen B, Lammert O, Madsen K, Sorensen P \& Webster J (1988) Relation between energy expenditure and body composition in man: specific energy expenditure in vivo of fat and fat-free tissue. European Journal of Clinical Nutrition 42, 301-305.

Hausberger FX \& Volz JE (1984) Feeding in infancy, adipose tissue cellularity and obesity. Physiology and Behavior 33, $81-87$.

Himms-Hagen J (1997) On raising energy expenditure in ob/ob mice. Science 276, 1132-1133.

Hoffmann L \& Klein M (1980) Die Abhängigkeit der Harnenergie vom Kohlenstoff- und Stickstoffgehalt im Ham bei Rindem, Schafen, Schweinen und Ratten (Urine energy content as determined by urine carbon and nitrogen in cattle, sheep, pigs and rats). Archive der Tierernährung 30, 743-750.

Iossa S, Lionetti L, Mollica MP, Barletta A \& Liverini G (1999) Energy intake and utilization vary during development in rats. Journal of Nutrition 129, 1593-1596.

Klaus S, Münzberg H, Trüloff C \& Heldmaier G (1998) Physiology of transgenic mice with brown fat ablation: obesity is due to lowered body temperature. American Journal of Physiology 274, R287-R293.

Knittle JL \& Hirsch J (1968) Effect of early nutrition on the development of rat epididymal fat pad: cellularity and metabolism. Journal of Clinical Investigation 47, 2091-2098.

Lambert EV \& Koeslag JH (1992) No persistent effect of preweaning nutrition on postweaning food intake, feeding efficiency, or body energy stores in Long-Evans rats. Physiology and Behavior 52, 363-372.

Martorell R, Stein AD \& Schroeder DG (2001) Early nutrition and later adiposity. Journal of Nutrition 131, 874S-880S.

Miller DS \& Personage SR (1972) The effect of litter size on subsequent energy utilization. Proceedings of the Nutrition Society 31, 30A-31A.

Oscai LB \& McGarr JA (1978) Evidence that the amount of food consumed in early life fixes appetite in the rat. American Journal of Physiology 235, R141-R144.

Parizková J \& Petrásek R (1979) Impact of early nutrition on later development of spontaneous physical activity and lipid metabolism. Nutrition and Metabolism 23, 266-274.

Plagemann A, Harder T, Rake A, Waas T, Melchior K, Ziska T, Rohde W \& Dorner G (1999) Observations on the orexigenic hypothalamic neuropeptide Y-system in neonatally overfed weanling rats. Journal of Neuroendocrinology 11, 541-546.

Plagemann A, Heidrich I, Gotz F, Rohde W \& Dorner G (1992) Obesity and enhanced diabetes and cardiovascular risk in adult rats due to early postnatal overfeeding. Experimental and Clinical Endocrinology 99, 154-158.

Prentice AM, Black AE, Coward WA, Davies HL, Goldberg GR, Murgatroyd PR, Ashford J, Sawyer M \& Whitehead RG (1986) High levels of energy expenditure in obese women. British Medical Journal 292, 983-987.

Proll J, Petzke KJ, Ezeagu IE \& Metges CC (1998) Low nutritional quality of unconventional tropical crop seeds in rats. Journal of Nutrition 128, 2014-2022.

Ravussin E \& Bogardus C (1989) Relationship of genetics, age and physical fitness to daily energy expenditure and fuel utilization. American Journal of Clinical Nutrition 49, 968-975.

Ravussin E, Burnand B, Schutz Y \& Jéquier E (1982) Twentyfour hour energy expenditure and resting metabolic rate in obese, moderately obese and control subjects. American Journal of Clinical Nutrition 35, 566-573.

Schmidt I, Schoelch C, Ziska T, Schneider D, Simon E \& Plagemann A (2000) Interaction of genetic and environmental programming of the leptin system and of obesity disposition. Physiological Genomics 3, 113-120.

Vickers MH, Breier BH, Cutfield WS, Hofman PL \& Gluckman PD (2000) Fetal origins of hyperphagia, obesity, and hypertension and postnatal amplification by hypercaloric nutrition. American Journal of Physiology 279, E83-E87.

Voits M, Forster S, Rodel S, Voigt JP, Plagemann A \& Fink H (1996) Obesity induced by unspecific early postnatal overfeeding in male and female rats: hypophagic effect of CCK-8S. Naunyn Schmiedeberg's Archives of Pharmacology 354, 374-378.

Weir JB (1949) New methods for calculating metabolic rate with special reference to protein metabolism. Journal of Physiology 109, $1-9$.

Wurtman JJ \& Miller SA (1976) Effect of litter size on weight gain in rats. Journal of Nutrition 106, 697-701.

You S, Gotz F, Rohde W \& Dorner G (1990) Early postnatal overfeeding and diabetes susceptibility. Experimental and Clinical Endocrinology 96, 301-306. 